\title{
On Computer Network Security Management and Technical Measures Enfeng Zhou
}

\author{
Dongfang College, Shandong University of Finance and Economics, Tai'an Shandong, 271000, \\ China
}

Key words: Computer network, Security management, Measure.

\begin{abstract}
As the development level of economy and society improves and technology changes quickly, human society informatization degree also deepens continuously. A distinguishing feature of information age is gradual promotion of internet and computer. Meanwhile, internet technology and computer technology also prevent a booming development trend. At present, internet and computer have successfully entered each field of production and life so that people's work, learning and living modes change greatly. Although internet technology and computer technology establish very close relationship with each field of social life, people cannot ignore potential safety hazard of internet and computer caused to people's production and life. On this basis, this paper aims to briefly introduce computer network security, analyze the reasons of computer network security, further discuss feasible measures to improve computer network security and propose suggestions on improving the level of computer network security.
\end{abstract}

\section{Introduction}

In recent years, internet technology and computer technology have shown a good development trend. The application fields of internet technology and computer technology are very wide. But, as internet technology and computer technology are generalized and their applications continuous innovate, computer network security gives rise to great attention in all sectors of society. In particular, computer network security accidents happen frequently. People pay more attention to computer network security level and take certain measures to enhance computer network security management, but the effect is not obvious. For such situation, the author will summarize computer network security, study the reasons for computer network security, explore the measures to enhance computer network security management and offer suggestions on orderly development of computer network.

\section{Brief introduction to computer network security}

Computer network security means computer data will not be damaged in the same network environment, and data confidentiality, integrity and availability can be ensured through relevant control measures of network technology and network management. Computer network security covers two aspects: logic security and physical security ${ }^{[1]}$. Logic security refers to confidentiality, integrity and availability of computer data. Physical security refers to protection of communication equipment related to computer network system and computer system.

At present, internet has covered each corner of earth. Internet application scope is very wide. It offers great convenience for people to achieve resource sharing and also provides strong guarantee for people to acquire information and transmit information. These are based on the connection between computer network and internet. Under such precondition, computer network security will be influence by many factors. Through theoretical research and analysis of practical experience, we can easily find that the features of internet are very significant and mainly cover the following aspects. Firstly, international feature. Since internet connects resources and people all over the world, internet 
system scale is very huge and the contents are also very complex. On this basis, computer network attack will show strong uncertainty, including attack object, attack content and attack initiator etc. Besides, this will expand the influence scope of attack. Both direct and indirect influences will result in very serious and global network security problem. Secondly, sharing feature. Since internet contains almost all fields and information in each period, the cost of network access becomes increasingly low, and the process becomes simpler and simpler, it is easy to reach the purpose of information resource sharing and spread dangerous information at the excuse of information sharing, such as computer virus. This to some extent threatens computer network security. Thirdly, openness feature. The operation of internet is free from time restriction and territorial limit. Anyone can log in websites and browse information anytime and anywhere. This leads to potential threat to computer network security ${ }^{[2]}$.

We can know from the above analysis that internet and computer depend o each other and supplement each other. However, the features of internet brings hidden dangers to computer network security.

\section{Problems of computer network security}

\section{Problems of computer operating system}

For a computer, the operating system plays a crucial role. The operating system manages the assembly of most programs in the computer. Only when the operating system is at good operation level can computer program operate smoothly. Thus, the normal operation of operating system offers strong guarantee for orderly work of computer system. As the assembly of computer system software, the operating system is responsible for providing operation interface for computer users, monitoring program operation in real time and managing resources stored in computer system. Thus, guaranteeing security degree of computer operating system is the precondition of ensuring computer network security. If the operating system goes wrong, for example, operating system software has some defects and potential safety hazard, and system design has loopholes which cannot be recovered, computer network security will be faced with huge threats ${ }^{[3]}$. The influence of operating system on computer network security cannot be ignored. It may even result in computer network paralysis.

\section{Prominent problems of computer data storage}

For a computer, the database is very enormous and can store massive data information, including all information acquired by people during website browsing. Currently, mainstream database plays a key role. On the one hand, mainstream database bears the responsibility of information management and offers guaranteed for information authenticity and accuracy. Meanwhile, mainstream database plays a great role for information storage. Although the position of mainstream database is very important, its function for computer network security is very limited. In computer operation, if users illegally operate the computer, these users will avoid the supervision of security core through illegal means and successfully filch the information stored in computer database and especially the information with high confidentiality level. This results in computer network security problem.

\section{Problems explored in computer network security}

Computer operation cannot be separated from internet network environment. Due to the features of internet, computer network environment will become very complicated when a computer is connected with network. In such circumstance, he sharing level of network information resources will improve significantly. At the same time, the transmission process and sharing process of network information will become more convenient. Webpage browsers may gain all kinds of information via internet in a short time ${ }^{[4]}$. Correspondingly, computer network security will be faced with very severe threats. Thus, security level of network environment directly decides computer network security level. Therefore, when the computer and network are connected, it is hard to ensure computer network 
security, and computer network security will be affected by internet features. To be more specific, internet features include international feature, sharing feature and openness feature.

\section{Measures to enhance computer network security}

\section{To improve technical level of computer network security}

As for enhancing computer network security management, network security technology is an important approach to improve computer network security level. To improve computer network security management, it is necessary to pay attention to enhancing technical level of computer network security. The specific work is as follows. Firstly, password technology can be introduced in computer network security management. Password technology supported by advanced science and technology contributes to expanding solutions to computer network security problem and offering strong guarantee for computer network security. For example, there is a digital signature technique in password technology. This technique has very obvious advantages. On the one hand, it can make sure the information stored in computer database will not be lost or filched ; on the other hand, it helps enhancement of verification level of file information management in computer network security management. The application of digital signature in computer network security management contributes to improving computer information transmission accuracy and timeliness and ensuring smooth implementation of work via internet and computer. Secondly, intrusion detection is conducted for computer network security ${ }^{[5]}$. As computer network is applied more and more widely, computer network intrusion behaviors happen frequently. Such behaviors result in property loss and information disclosure. These not just damage personal property safety and information security, but also generate very adverse effects on national safety. Since intrusion behaviors are not detected effectively in time, these intrusion behaviors cause very serious consequences. Thus, it is necessary to detect intrusion behaviors in computer network security management, i.e. intrusion detection. The detection process is as follows: important information stored in computer system and some network behaviors are deeply studied and detected strictly, and computer system and network operation behaviors are monitored in real time on the basis of research and detection. Intrusion detection contributes to effectively maintaining computer network security. Compared with firewall, the advantages of intrusion detection are very prominent. Intrusion detection can assist computer system in scientifically and rationally solving network security problem and then greatly improve computer system security level. Thirdly, network virus resistance level improves. Computer network security is seriously threatened by computer virus. In internet, the forms of viruses are diversified. The computer may contract the virus very easily, and the virus spreads through file transmission and other ways. Thus, virus influence scope expands. Hence, enhancing the ability of computer network to handle virus has become an important topic of current computer network security management. In order to strengthen the ability of computer network to cope with virus invasion, the computer needs to continuously monitor and scan files and data on the server, search and kill Trojan virus and flexibly handle malicious program intrusion. Fourthly, database system and operating system are upgraded. Computer operating system may easily breed virus. To effectively resist virus attack, it is necessary to deeply study and develop operating system, improve the property of operating system and enhance security level of operating system. Meanwhile, relevant personnel also need to upgrade computer database and offer fundamental guarantee for database information security.

\section{To implement network security management}

To improve computer network security management level, on the one hand, it is necessary to establish and improve laws and regulations of network security management, carry out publicity activity and enhance people's network security awareness; on the other hand, appropriate measures should be taken to improve technical level of network security management. Management work should lay emphasis on the following two aspects. Firstly, intensify netizens' network security awareness, make the public have a specific cognition of significance of legal education, carry out 
network activity in strict accordance with laws and regulations, enhance self-discipline awareness, avoid illegal operation and form good atmosphere of maintaining computer network security. Secondly, when administrators of computer network system work, they should take the initiative to improve their management ability and consciously enhance professional quality and comprehensive quality. Moreover, normative working system should be formulated for computer network security in order to offer effective guarantee for computer network security.

\section{To create favorable network environment}

To guarantee network security in computer operation period, orderly network environment should be constructed. Thus, it is required to offer practical guarantee for security of network computer and its room environment. Thus, the computer needs to be placed in relatively stable environment to avoid the influence of harmful factors. Meanwhile, appropriate computer network installation environment should be chosen to prevent the interference of vibration source and noise source. In addition, management system should be established for computer room, and there should be specific provisions on persons on the machine room and machine use. Without the permit of the administrator, anyone shall not enter the machine room. To guarantee security of important network computer, necessary security protection measures should be used for the machine room. Besides, anti-theft system should be installed to prevent bad influence on computer network security.

\section{Conclusion}

In conclusion, many factors will influence computer network security. Thus, some problems of computer network security gradually stand out. In a bid to drive further development of computer network, proper measures must be taken to solve these problems. Meanwhile, all sectors of society should pay more attention to computer network security. The problems of computer network security cover operating system, data storage and network environment. As internet technology and computer technology change quickly, all fields of social life increasingly depend on computer network which generates huge influence on people's production and life. The problems of computer network security become more severe, so effective measures must be taken, such as improving technical level of network security and paying attention to network security environment of network security management and construction. Moreover, it is also necessary to establish and improve laws and regulations of computer network security, intensify netizens' legal consciousness and safety awareness, create a secure and harmonious network environment and provide practical guarantee for computer network security.

\section{References}

[1] Liu Wenjian, On precautionary measure to intensify computer network security management, Corporate Culture (III), 2016(4):249-249.

[2] Liang Xingxiang, Implementation and countermeasures of computer network security management, China Management Informationization, 2013(19):92-94.

[3] Liu Liwei, Analysis of computer network security management technology, Beauty and Era City, 2013(11):102-102.

[4] Ma Yushan, Song Caiya, On how to achieve enterprise computer network security management, Computer Knowledge and Technology, 2013(31):6973-6974,6977.

[5] Fan Yan, Study on computer network security management, Oriental Enterprise Culture, 2014(18):180-180. 